\title{
The Aggregation and Dissociation Properties of a Low Molecular Weight Mannose 6-Phosphate Receptor from Bovine Testis ${ }^{1}$
}

\author{
Maomi Li, Jack J. Distler, and George W. Jourdian ${ }^{2}$ \\ Department of Biological Chemistry, and the Rackham Arthritis Research Unit, Department of Internal Medicine, \\ The University of Michigan Medical School, Ann Arbor, Michigan 48109
}

Received April 3, 1990, and in revised form July 26, 1990

The aggregation state of low molecular weight mannose 6-phosphate receptor from bovine testis was determined in membrane preparations and in purified soluble preparations. The effect of aggregation on binding of the receptor to immobilized pentamannose 6-phosphate was also examined. Nonreducing SDS-PAGE followed by immunoblotting revealed that interchain disulfide bonds exist in detergent-solubilized and purified receptor preparations, but not in membrane-associated receptor. Reduction of the receptor with dithiothreitol abolished its ligand binding activity and drastically altered its ability to bind antibodies. The results of receptor crosslinking and molecular sieving chromatography studies suggest that the receptor exists in membranes as a noncovalently linked dimer and in solution as oligomeric forms, largely as a tetramer. The formation of the tetramer is affected by the concentration of the receptor, but not by its solubilization from membranes with detergent, nor by the presence of mannose 6-phosphate. Mono-, di-, and tetramer forms of ${ }^{125}$ I-labeled receptor were separated by molecular sieving chromatography and examined for their ability to bind to immobilized ligand, agarose-pentamannosephosphate. The order of binding observed was tetramer $>$ dimer $>$ monomer. Binding of the monomer and dimer to immobilized ligand was dependent on the presence of divalent cations while the tetramer had little requirement for divalent cations. @1990 Academic Press, Inc.

Covalently bound mannose 6-phosphate (Man-6-P) ${ }^{3}$ residues are present on $\mathrm{N}$-linked oligosaccharides of ly-

\footnotetext{
${ }^{1}$ This work was supported by NIH Grant AR 10531 and in part by a grant from the Arthritis Foundation, Michigan Chapter.

${ }_{2}$ To whom correspondence should be addressed.

${ }^{3}$ Abbreviations used: Man-6-P, mannose 6-phosphate; MPR-1, high molecular weight mannose 6-phosphate receptor $(215 \mathrm{kDa})$; MPR-2, low molecular weight mannose 6-phosphate receptor (41-46
}

sosomal acid hydrolases (1). The intracellular targeting of extracellular and newly synthesized acid hydrolases to lysosomes is mediated by the specific recognition of this monophosphoester by membrane-associated mannose 6-phosphate receptors $(2,3)$. Two mannose 6-phosphate receptors have been isolated and characterized. The first described mannose 6-phosphate receptor (MPR-1) ${ }^{4}$ was isolated from bovine liver membrane preparations (4) and from rat Swarm chondrosarcoma chondrocytes (5). This receptor is a glycoprotein with a reported molecular mass of approximately $215 \mathrm{kDa}$. Binding of MPR-1 to ligands is not dependent on divalent cations (4). A second mannose 6-phosphate receptor (MPR-2) has been isolated from a number of tissues and cell types; these include murine macrophages and bovine liver (6), and bovine testis (7). The apparent molecular mass of this receptor is $41-46 \mathrm{kDa}$ and its affinity for ligand is dependent on divalent cations (6).

The genes that express MPR-1 and MPR-2 have been cloned (8-11). The predicted sequences indicate that the 145 amino acid extracytoplasmic domain (ligand binding domain) of MPR-2 is homologous to the 15 repeating extracytoplasmic domains found in MPR-1. Despite the large difference in the size of the ligand binding domains, each receptor exhibits similar ligand specificities (1214). MPR-2 has been found to exist as a dimer in membranes of cultured cell lines $(14,15)$. The aggregation state of the purified receptor preparations reported by several laboratories differ, i.e., MPR-2 from human liver exists as a tetramer (16), and bovine MPR-2 translated in Xenopus laevis oocytes as a dimer (15). A truncated human receptor in which the transmembrane domain

\footnotetext{
kDa); DSP, dithiobis-(succinimidylpropionate); PBS, phosphatebuffered saline; SDS-PAGE, sodium dodecyl sulfate-polyacrylamide gel electrophoresis; DTT, dithiothreitol; BSA, bovine serum albumin.

${ }^{4}$ MPR-1 and MPR-2 are often referred to in the literature as Man6-P receptor ${ }^{\mathrm{CI}}$ and Man-6-P receptor ${ }^{\mathrm{CD}}$, respectively.
} 
was deleted existed as a homodimer (17), but a truncated bovine receptor was present as a monomer (15). The reasons for these apparent differences in oligomeric states of MPR-2 and their effects on ligand binding activities of the receptor have not been resolved.

The present studies address these considerations. The results of experiments designed to examine (i) the oligomeric state of membrane-associated and affinity-purified MPR-2 from bovine testes; (ii) factors affecting the aggregation and dissociation of MPR-2; and (iii) the effect of the oligomeric state of MPR-2 on its ability to bind ligands carrying covalently bound Man-6-P residues are summarized. The results of preliminary studies have been reported (18).

\section{MATERIALS AND METHODS}

Mannose 6-phosphate, dithiothreitol ( $\left.\mathrm{D}^{\prime} \mathrm{T} \mathrm{T}\right)$, and protein A were obtained from Sigma; dithiobis-(succinimidylpropionate) (DSP), Pierce; and nitrocellulose membranes, Millipore. All other materials and reagents were of the highest grade available. $\mathrm{Na}^{125}$ I was purchased from Amersham. Male New Zealand white rabbits $(6 \mathrm{lb})$ were obtained from Shankins (Detroit, MI). The affinity matrix used for the isolation of mannose 6-phosphate receptors, agarose-pentamannosephosphate, was prepared as previously described (19).

Purification and iodination of bovine testis MPR-2. MPR-2 was purified from frozen bovine testes and iodinated with ${ }^{125} \mathrm{I}$ by previously described methods (20).

Preparation of antiserum against native and denatured MPR2. Antiserum against nondenatured MPR-2 was prepared as previously described (19). Antiserum directed against denatured MPR-2 was prepared in the following manner. Purified MPR-2 (1 mg) was heated at $60^{\circ} \mathrm{C}$ for $10 \mathrm{~min}$ in SDS-PAGE sample buffer, and subjected to preparative SDS-PAGE under reducing conditions. MPR-2 was detected by staining the gels with Coomassie blue. Bands corresponding to MPR-2 were cut from the gel and eluted by the procedure of Lazarides (21). Male rabbits were immunized by the procedure of Hurn and Chantler (22). MPR-2 (100 $\mu$ g contained in $0.5 \mathrm{ml}$ of gel elution buffer) was emulsified in $1.5 \mathrm{ml}$ of Freund's complete adjuvant and multiply injected intramuscularly into the legs of each animal $(0.5 \mathrm{ml} / \mathrm{leg})$. The rabbits were again challenged in the same fashion at 4 - and 8 -week intervals after the initial injection with one-half the volume of the antigen-adjuvant emulsion used for the initial injections. Blood samples were removed 1 week after each booster injection and assayed for antibody production by the double diffusion procedure of Ouchterlony (23).

Reduction of $\left[{ }^{125} I\right] M P R-2$ with dithiothreitol and analysis of ligand and antibody binding affinity. $\quad\left[{ }^{125} \mathrm{I}\right] \mathrm{MPR}-2(120,000 \mathrm{cpm}, 25 \mathrm{ng})$ was incubated in $0.4 \mathrm{ml}$ of a buffer comprised of $50 \mathrm{mM}$ Tris- $\mathrm{HCl}(\mathrm{pH} 7.4)$, $150 \mathrm{mM} \mathrm{NaCl}, 0.05 \%$ Triton X-100, and varying amounts of DTT $(0-$ $10 \mathrm{mM})$ at $37^{\circ} \mathrm{C}$ for $30 \mathrm{~min}$. An aliquot of each reaction mixture $(0.2 \mathrm{ml}$ $60,000 \mathrm{cpm}$ ) was placed on a $1 \times 1.5-\mathrm{cm}$ column containing agarosepentamannosephosphate affinity matrix previously equilibrated with buffer $\mathrm{A}\left(150 \mathrm{mM} \mathrm{NaCl}, 0.02 \% \mathrm{NaN}_{3}, 0.05 \%\right.$ Triton $\mathrm{X}-100$, and $50 \mathrm{mM}$ imidazole, $\mathrm{pH}$ 6.5) containing $10 \mathrm{mM} \mathrm{MnCl}$. Each column was washed with $4 \mathrm{ml}$ of buffer A containing $10 \mathrm{mM} \mathrm{MnCl}$ and eluted with $4 \mathrm{ml}$ of same buffer containing $5 \mathrm{mM}$ Man-6-P. For immunoprecipitation, the treated [ $\left.{ }^{125} \mathrm{I}\right] \mathrm{MPR}-2(40 \mu \mathrm{l}, 12,000 \mathrm{cpm})$ was incubated at $25^{\circ} \mathrm{C}$ for $2 \mathrm{~h}$ with $2 \mu$ l of anti-nondenatured MPR- 2 or $1 \mu \mathrm{l}$ of anti-denatured MPR2 antiserum, $50 \mu \mathrm{l}$ of $10 \%$ IgGsorb, and $150 \mu \mathrm{l}$ of a buffer comprised of

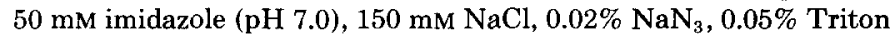
$\mathrm{X}-100$, and $0.5 \mathrm{mg} / \mathrm{ml}$ bovine serum albumin. Three milliliters of buffer were added to each incubation tube, the tubes were mixed, and IgGsorb-antibody-[ ${ }^{125}$ I]MPR-2 complex was precipitated by centrifu- gation for $4 \mathrm{~min}$ at $2000 \mathrm{~g}$. The supernatant was removed by aspiration and the radioactivity associated with the precipitate quantitated in a gamma spectrometer.

Preparation of bovine testis membranes and membrane extracts for crosslinking studies. Frozen testes $(10 \mathrm{~g})$ were suspended in $20 \mathrm{ml}$ of PBS ( $150 \mathrm{~mm} \mathrm{NaCl}$ and $50 \mathrm{~mm}$ sodium phosphate, $\mathrm{pH} 7.0)$ and homogenized with a motor driven Potter-Elvehjem homogenizer fitted with a teflon pestle with a chamber clearance of 0.13 to $0.18 \mathrm{~mm}$. The homogenate was centrifuged at $4^{\circ} \mathrm{C}$ for $5 \mathrm{~min}$ at $800 \mathrm{~g}$. The supernatant was removed and centrifuged for $30 \mathrm{~min}$ at $110,000 \mathrm{~g}$. The resulting pellet was washed, resuspended in PBS, and again pelleted by centrifugation. The membranes were either suspended in PBS and used directly for crosslinking experiments, or the receptor was solubilized from the membranes by extraction with PBS containing $1 \%$ Triton $\mathrm{X}-100$ for $1 \mathrm{~h}$ and centrifuged for $30 \mathrm{~min}$ at $110,000 \mathrm{~g}$. The supernatant was used directly for crosslinking experiments.

Crosslinking of MPR-2. Each reaction mixture $(100 \mu \mathrm{l})$ contained $0.65 \mathrm{mg}$ membrane protein in PBS or $25 \mu \mathrm{g}$ purified MPR-2 in PBS containing $0.05 \%$ Triton X-100. DSP in $2 \mu \mathrm{l}$ of dimethyl sulfoxide was added to the reaction mixtures at final concentrations of 0.5 to $4.0 \mathrm{mM}$ and the mixtures were incubated at $25^{\circ} \mathrm{C}$ for $30 \mathrm{~min}$. The reactions were stopped by addition of an equal volume of double strength SDSPAGE sample buffer (10\% glycerol, $0.004 \%$ bromphenol blue, $3 \%$ SDS, $62.5 \mathrm{mM}$ Tris- $\mathrm{HCl}, \mathrm{pH}$ 6.8). The resulting preparations were boiled for $4 \mathrm{~min}$, subjected to SDS-PAGE, and immunoblotted. Manganese chloride was added to some reaction mixtures at a final concentration of $10 \mathrm{mM}$. In these reaction mixtures, the sodium phosphate present in the buffer described above was replaced with $50 \mathrm{mM}$ Hepes.

$S D S-P A G E$ and immunoblotting. SDS-PAGE was performed by the method of Laemmli (24). Immunoblotting was performed by a modification of the procedure of Burnette (25). Protein bands were transferred to nitrocellulose membranes and the membranes blocked with $5 \%$ BSA contained in a buffer composed of $150 \mathrm{mM} \mathrm{NaCl}$ and 50 $\mathrm{mM}$ Tris- $\mathrm{HCl}(\mathrm{pH} 7.4)$ at room temperature for $1.5 \mathrm{~h}$ with agitation. The nitrocellulose sheets were then incubated at room temperature with continued agitation for $2 \mathrm{~h}$ in $10 \mathrm{ml}$ of a buffer containing $0.25 \%$ gelatin, $150 \mathrm{mM} \mathrm{NaCl}, 50 \mathrm{mM}$ Tris-HCl, pH 7.4 (buffer B), and $50 \mu \mathrm{l}$ of antiscrum against denatured MPR 2 antiserum. $\Lambda$ fter four washes of $15 \mathrm{~min}$ each in buffer $\mathrm{B}$, the sheets were incubated at room temperature for $1 \mathrm{~h}$ with $\left[{ }^{125} \mathrm{I}\right]$ protein $\mathrm{A}\left(8 \times 10^{5} \mathrm{cpm} / \mathrm{ml}\right)$ contained in $5 \mathrm{ml}$ of buffer $B$. Finally, the nitrocellulose sheets were washed four additional times in buffer B, air dried, and autoradiographed over Kodak X-Omat AR film in cassettes equipped with Du Pont Lightening Plus intensifying screens.

Molecular sieving chromatography of MPR-2. ${ }^{125} \mathrm{I}$-labeled or unlabeled MPR-2 was applied to a $1.6 \times 165-\mathrm{cm}$ column of Ultrogel AcA 34 preequilibrated and eluted with a buffer comprised of $0.02 \% \mathrm{NaN}_{3}$, $0.1 \%$ taurodeoxycholate, $150 \mathrm{mM} \mathrm{NaCl}$, and $50 \mathrm{~mm}$ imidazole- $\mathrm{HCl}$, $\mathrm{pH}$ 7.0. The column was calibrated and run under the conditions previously described (20).

\section{RESULTS}

MPR-2 interchain disulfide bond formation. When purified MPR-2, devoid of MPR-1, was subjected to SDS-PAGE under reducing conditions only a single Coomassie blue staining band with an apparent molecular mass of $42 \mathrm{kDa}$ was detected. When run under nonreducing conditions, three bands approximating 40, 80, and $120 \mathrm{kDa}$, respectively, were detected (Fig. 1A). The monomer migrated slightly faster under nonreducing conditions, suggesting it contains intrachain disulfide bonds. We suggest the higher molecular mass forms were dimer and trimer forms of MPR-2 that contained interchain disulfide bonds. 


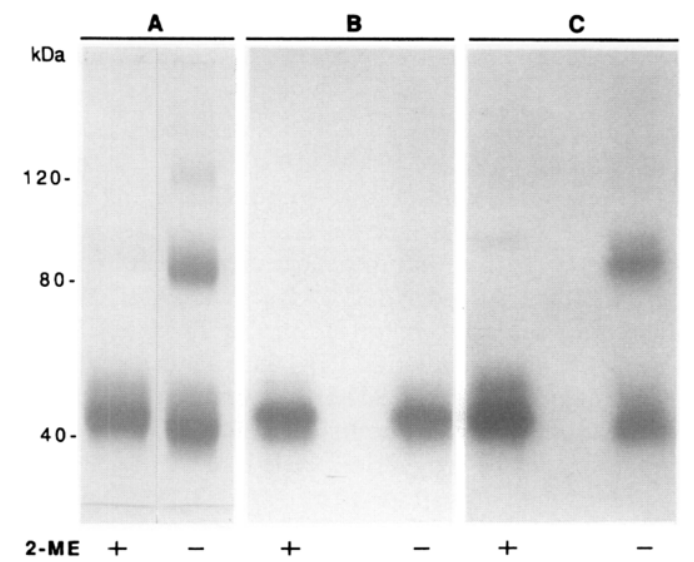

FIG. 1. SDS-PAGE analysis of MPR-2. (A) Purified bovine testis MPR-2 was subjected to SDS-PAGE ( $8 \%$ gel) in the presence $(+)$ and absence $(-)$ of 2-mercaptoethanol (2-ME). Protein was detected with Coomassie brilliant blue stain. Bovine testis membrane preparations (B) and membrane extracts (C) were prepared as described in the text. The samples were boiled with an equal volume of SDS-PAGF sample buffer $(2 \times)$ in the presence and absence of $5 \% 2$-mercaptoethanol, subjected to SDS-PAGE ( $8 \%$ gel), immunoblotted using anti-denatured MPR-2 antibody, and autoradiographed.

To assess whether interchain disulfide bonds exist in membrane-associated MPR-2 or, alternatively, were artifacts of the purification procedure, the following experiments were conducted. Freshly prepared bovine testis membranes were boiled with SDS-PAGE sample buffer in the presence and absence of 2-mercaptoethanol and subjected to SDS-PAGE. After immunoblotting only a single species of MPR-2, approximating $42 \mathrm{kDa}$, was detected under reducing and nonreducing conditions (Fig. 1B). When membrane preparations were extracted with Triton X-100 and then boiled with SDS-PAGE buffer under reducing conditions, a single band of MPR-2 with an apparent molecular mass of $42 \mathrm{kDa}$ was detected. In contrast, nonreduced material yielded an additional band of apparent molecular mass of $80 \mathrm{kDa}$ (Fig. 1C). These results suggest that interchain disulfide bonds are not present in membrane-associated MPR-2 but are formed during the solubilization process.

The effect of DTT on ligand and antibody binding to MPR-2. Results obtained when solubilized MPR-2 was subjected to SDS-PAGE suggested that MPR-2 preparations contained not only interchain disulfide bonds, but intrachain disulfide bonds as well since nonreduced receptor exhibited a slightly higher mobility than reduced receptor. Intrachain disulfide bonds could promote proper folding of the receptor to maintain biologic function. This hypothesis was assessed by determining the ability of receptor to bind (i) ligand and (ii) antibodies against the receptor after reduction with DTT. The binding of $\left.{ }^{125} \mathrm{I}\right] \mathrm{MPR}-2$ to an agarose-pentamannosephosphate affinity column was diminished $>80 \%$ by treatment with $5 \mathrm{~mm}$ DTT for $30 \mathrm{~min}$ (Fig. 2A). Binding of MPR-2 to antiserum raised against non- denatured MPR-2 decreased rapidly with increasing concentrations of the reductant (Fig. 2B). Conversely, binding of reduced $\left[{ }^{125} \mathrm{I}\right] \mathrm{MPR}-2$ to antibody raised against denatured MPR-2 increased with increasing concentrations of DTT. Taken together, these results strongly suggest that disulfide bonds are important not only for maintaining the biologically active conformation of the receptor but for recognition of its "native" antigen epitopes as well.

Oligomeric state of solubilized and membrane-associaled MPR-2. Purified MPR-2 was crosslinked with the homobifunctional crosslinking reagent, DSP, and subjected to SDS-PAGE under nonreducing conditions (DSP forms reducible crosslinks, therefore, crosslinked samples were not reduced). Four bands with apparent average molecular masses of $40,80,120$, and $160 \mathrm{kDa}$, respectively, corresponding to putative monomer, dimer, trimer, and tetramer forms of MPR-2 were observed after crosslinking (Fig. 3A). As the concentration of DSP was increased, the levels of the dimer and tetramer forms increased and the levels of trimer decreased. Above a final concentration of $1 \mathrm{mM}$ DSP, no further increase in crosslinked receptor was observed and most of the receptor existed as dimer and tetramer. Exchange of Triton $\mathrm{X}-100$ with sodium taurodeoxycholate, or the addition
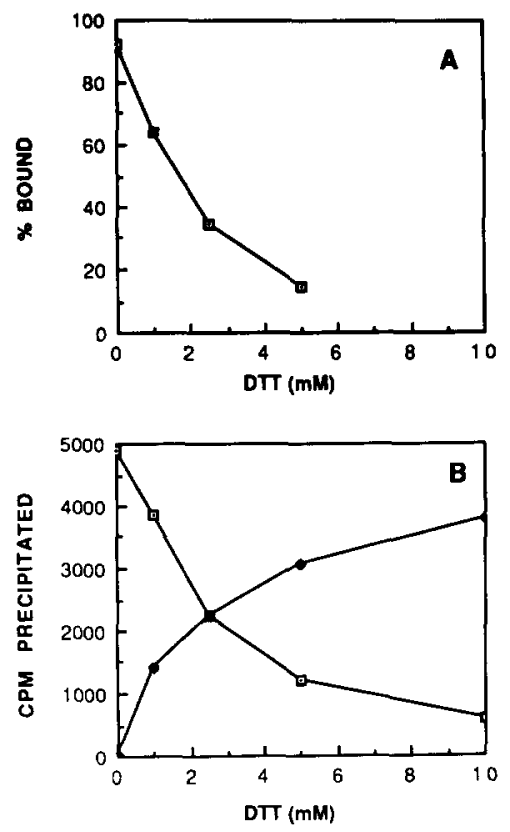

FIG. 2. Effect of DTT on the binding of MPR-2 to affinity column and antibodies. (A) $\left[{ }^{125}\right.$ I] MPR-2 was treated with increasing concentrations of DTT and chromatographed on agarose-pentamannosephosphate aftinity columns as described under Materials and Methods. The values shown on the ordinate are expressed as cpm eluted/(cpm washed + cpm eluted). (B) DTT-treated [ $\left.{ }^{125} \mathrm{I}\right] \mathrm{MPR}-2$ $(12,000 \mathrm{cpm})$ was immunoprecipitated with antiserum raised against nondenatured MPR-2 ( $\square$ ) or antiserum raised against denatured MPR-2 ( $\square$ ), as described under Materials and Methods. The values reported are the averages of duplicate values which varied $<10 \%$. 


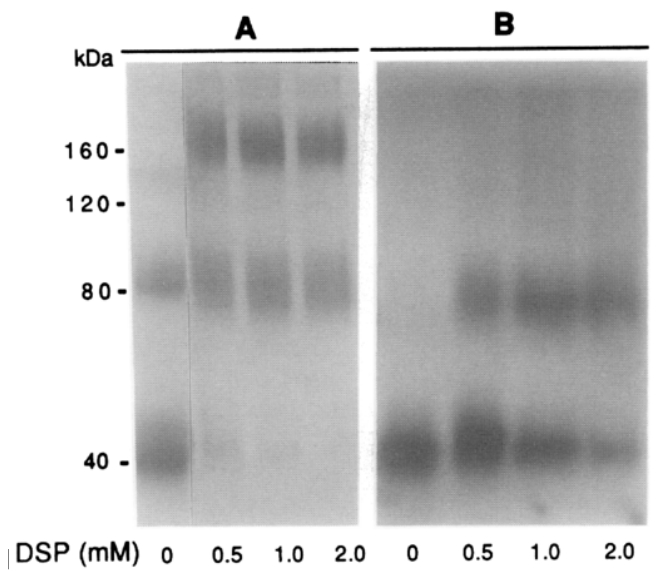

FIG. 3. Crosslinking of purified or membrane-bound MPR-2. (A) Purified MPR-2 $(25 \mu \mathrm{g}$ in $100 \mu \mathrm{l}$ of PBS containing $0.1 \%$ Triton X100) was crosslinked with DSP at the indicated concentrations as described in the text. Aliquots of each reaction mixture were subjected to SDS-PAGE electrophoresis ( $8 \%$ gel) under nonreducing conditions. Protein bands were detected by Coomassie blue staining. (B) Bovine testis membranes were prepared as described in the text. Membranes (0.65 mg protein) were suspended in $100 \mu \mathrm{l}$ of PBS. Varying amounts of DSP were added at the final concent rations indicated and incubated at $25^{\circ} \mathrm{C}$ for $30 \mathrm{~min}$. The reactions were stopped by addition of $100 \mu \mathrm{l}$ of SDS-PAGE sample buffer and boiling for $3 \mathrm{~min}$. Aliquots of each reaction mixture were submitted to SDS-PAGE ( $8 \%$ gel) under nonreducing conditions and immunoblotted as described in the text.

of $5 \mathrm{mM} \mathrm{Man-6-P}$ or $10 \mathrm{mM} \mathrm{MnCl}{ }_{2}$, did not alter the relative ratio of the crosslinked products (data not shown).

To assess the aggregation state of membrane-bound MPR-2, bovine testis membranes were crosslinked with DSP and subjected to SDS-PAGE. MPR-2 was detected by immunoblotting with antiserum raised against denatured MPR-2. As the concentration of DSP increased, the amount of monomer decreased and, concomitantly, the amount of dimer increased; neither trimer nor tetramer forms were detected (Fig. 3B).

Formation of oligomeric forms of MPR-2. Since the tetramer was detected in purified MPR-2 preparations but not in membrane preparations, it was of interest to determine which step in the purification was responsible for the formation of the tetramer. Membranes were extracted in PBS containing 1\% Triton X-100 as described under Materials and Methods. Aliquots of the extract were immediately crosslinked with DSP in the presence, or absence, of Man-6-P and the crosslinked products were subjected to SDS-PAGE and immunoblotted. A major band of approximately $80 \mathrm{kDa}$ was detected on SDS-PAGE gels run under nonreducing conditions, suggesting that the dimer, but not higher oligomers was present (Figs. 4A and 4B). Noncrosslinked extracts from the same preparation were applied to an agarose-pentamannosephosphate affinity column. The column was washed with PBS containing $1 \%$ Triton $\mathrm{X}-100$ and eluted with buffer containing $5 \mathrm{mM}$ Man-6-P. The eluate containing the same concentration of MPR-2 as that present in the membrane extract was cross-linked with DSP. In contrast to the immunoblot profile obtained from the membrane extract, affinity-purified MPR-2 yielded an additional band with an apparent molecular mass of $160 \mathrm{kDa}$ (Fig. 4C). These results suggest that at least a portion of the MPR-2 existed as a tetramer after affinity purification.

Molecular sieving of MPR-2 aggregates. When $\left[{ }^{125} \mathrm{I}\right]-$ MPR-2 $\left(1.6 \times 10^{6} \mathrm{cpm}, 0.33 \mu \mathrm{g}\right)$ was applied to a calibrated column of Ultrogel AcA 34 and eluted as described under Materials and Methods, three ${ }^{125}$ I-labeled peaks ( $a, b$, and $c$ ) were obtained (Fig. 5). Because of the positions of elution of peaks $a, b$, and $c$, the peaks were presumed to represent tetramer, dimer, and monomer, respectively. For example, peak a comigrated on the Ultrogel AcA 34 column with a sample of high concentration, nonlabeled MPR-2 which was predominantly tetramer as determined by crosslinking studies (not shown). Peak c contained only monomer when analyzed by SDS-PAGE in the presence or absence of 2-mercaptoethanol (Fig. 6), whereas peak b yielded disulfidelinked dimer and peak a dimer, trimer, and tetramer in addition to monomer under nonreducing conditions. These results suggest that peaks $a, b$, and c contained tetramer, dimer, and monomer forms of MPR-2, respectively.

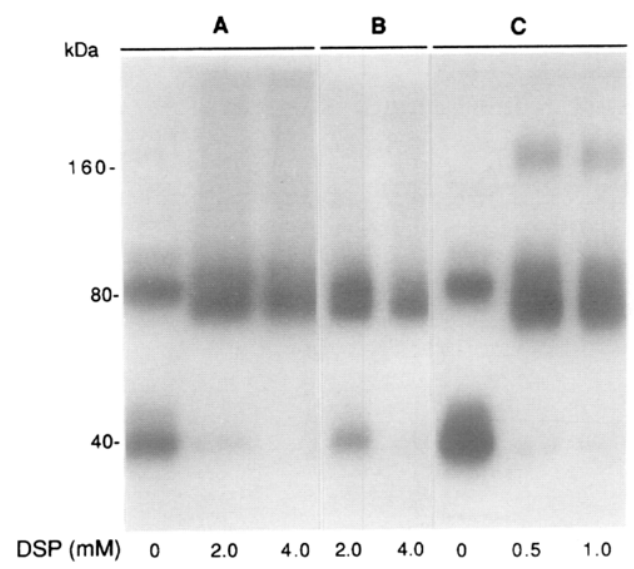

FIG. 4. Crosslinking of Triton X-100-treated bovine testis membrane extracts and affinity-purified MPR-2. (A) Bovine testis membranes were solubilized with PBS containing $1 \%$ Triton X-100. The extracts were crosslinked with varying concentrations of DSP as shown. (B) The extract was incubated with $5 \mathrm{mM}$ Man-6-P at $4^{\circ} \mathrm{C}$ for $4 \mathrm{~h}$ and crosslinked with DSP. (C) The membrane extract $(8 \mathrm{ml})$ was applied to an agarose-pentamannosephosphate affinity column $(1 \times 1$ $\mathrm{cm}$ ). The column was washed with $10 \mathrm{ml}$ of PBS containing $1 \%$ Triton $\mathrm{X}-100$ and eluted with $8 \mathrm{ml}$ of the same buffer containing $5 \mathrm{mM}$ Man6-P. The affinity chromatography was completed in $4 \mathrm{~h}$ and aliquots of the eluate were crosslinked with DSP immediately. In each of the above preparations the MPR-2 concentration approximated $3.5 \mu \mathrm{g} /$ $\mathrm{ml}$. The reaction mixtures were stopped by boiling with an equal volume of double strength sample buffer (lacking 2-mercaptoethanol), submitted to SDS-PAGE ( $8 \%$ gel), immunoblotted, and detected by autoradiography. 


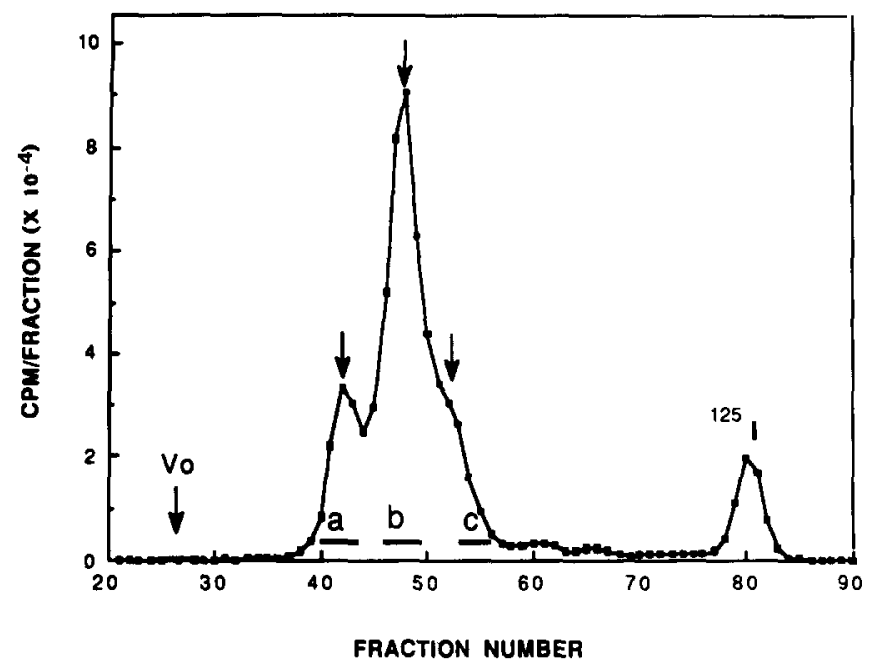

FIG. 5. Fractionation of $\left[{ }^{125} \mathrm{I}\right] \mathrm{MPR}-2$ on Ultrogel AcA $34 .\left[{ }^{125} \mathrm{I}\right]-$ MPR-2 $\left(1.6 \times 10^{6} \mathrm{cpm}, 0.33 \mu \mathrm{g}\right.$ protein $)$ was placed on a standardized Ultrogel AcA 34 column $(1.6 \times 165 \mathrm{~cm})$ and eluted as described in the text. The peaks containing receptor $(a, b$, and $c)$ were pooled as indicated and concentrated.

Dissociation of MPR-2 aggregates. When peak c was rechromatographed on the same column, it eluted in the same elution volume as initially (Fig. 7). Eighty-six percent of peak b eluted in the same volume as it did initially and $12 \%$ eluted in the same position as peak c. Peak a, when rechromatographed, was resolved into three peaks corresponding to peaks a (52\%), b (34\%), and c (14\%), respectively. These results suggest that under the experimental conditions utilized, the [ $\left.{ }^{125} \mathrm{I}\right] \mathrm{MPR}-2$ tetramer dissociated into the dimer and monomer, but the monomer and dimer did not associate to form the tetramer.

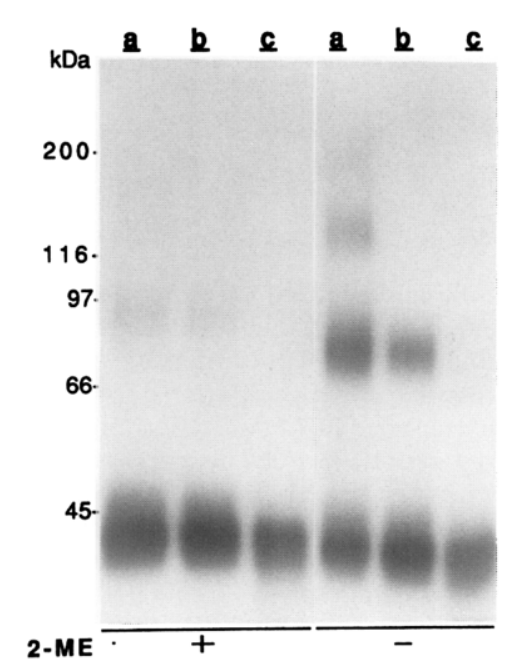

FIG. 6. SDS-PAGE of ${ }^{125}$ I-labeled peaks $a, b$, and $c$ from the Ultrogel AcA 34 column (Fig. 5). Peaks a, b, and $c$ were subjected to SDSPAGE (8\% gel) in the presence ( 1 ) or absence ( ) of 2-mercaptoethanol and the gel was dried and autoradiographed.
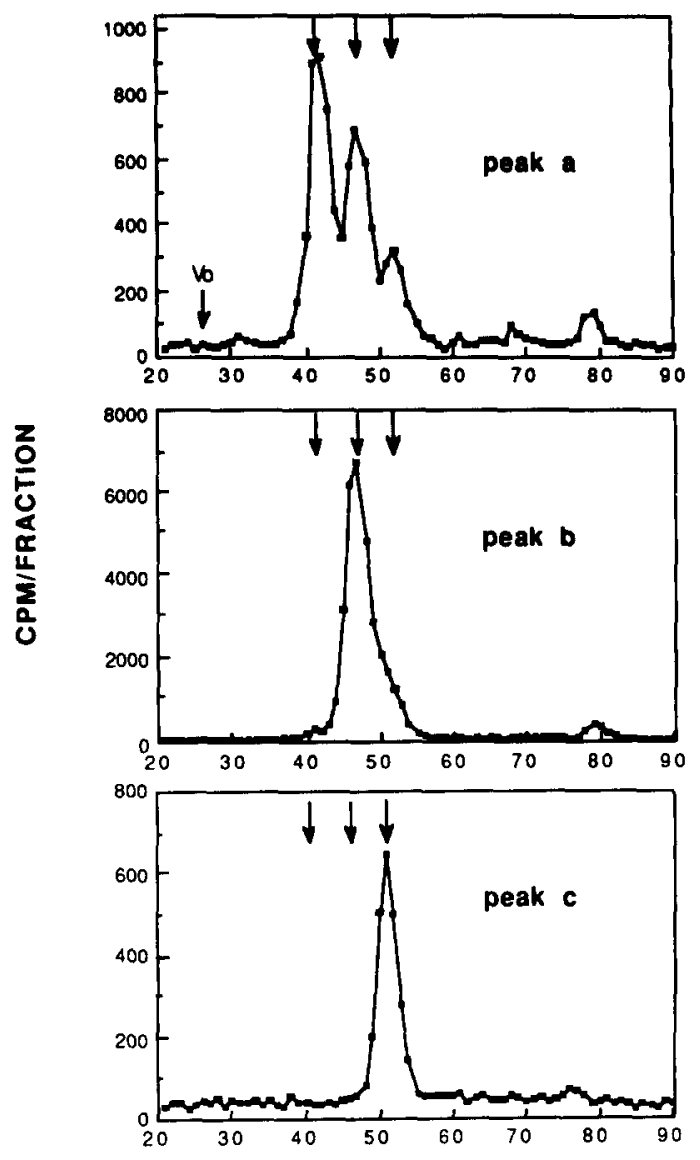

FRACTION NUMBER

FIG. 7. Rechromatography of ${ }^{125}$ I-labeled peaks a, b, and c (Fig. 5) on the standardized Ultrogel AcA 34 column. The arrows indicate the initial migration positions of peaks $a, b$, and $c$ (Fig. 5) on the same column.

When [ $\left.{ }^{125} \mathrm{I}\right] \mathrm{MPR}-2$ (11 ng) was mixed with nonlabeled MPR-2 $(0.5 \mathrm{mg})$ and the mixture subjected to molecular sieving, $>90 \%$ of the radioactive material comigrated with nonlabeled MPR-2, i.e., as peak a (not shown). When MPR-2 $(0.5 \mathrm{mg})$ was subjected to the same conditions used to radioiodinate the receptor and subjected to molecular sieving on the same column, it also eluted as a single peak corresponding to peak a (data not shown). Together, these results suggest that the aggregated forms of MPR-2 exist in solutions of relatively high receptor concentration and that MPR-2 dissociates in dilute solution. This phenomenon is independent of the iodination procedure.

Effect of aggregation on ligand binding. The ability of each aggregate form (peak a, b, and c, Fig. 5) to bind to immobilized ligand was examined. An aliquot of each peak, containing approximately equal amounts of ${ }^{125} \mathrm{I}$, was subjected to chromatography on the affinity matrix, agarose-pentamannosephosphate (Fig. 8). In the absence of added $\mathrm{MnCl}_{2}, 65,32$, and $4 \%$, respectively, of 

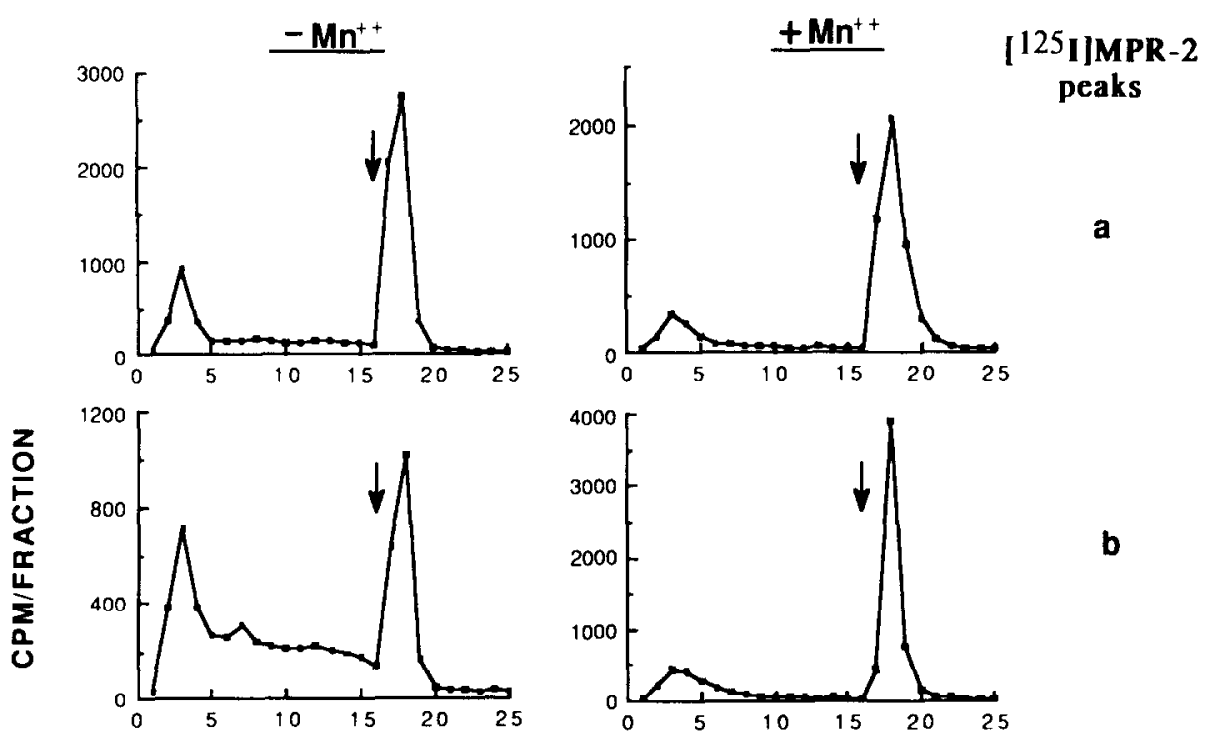

a

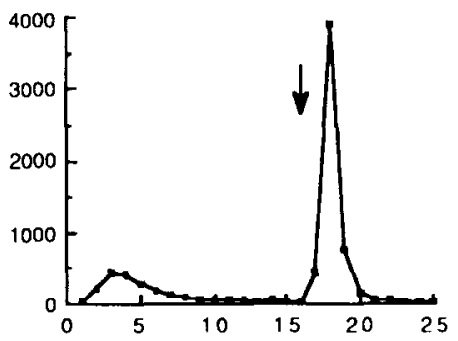

b
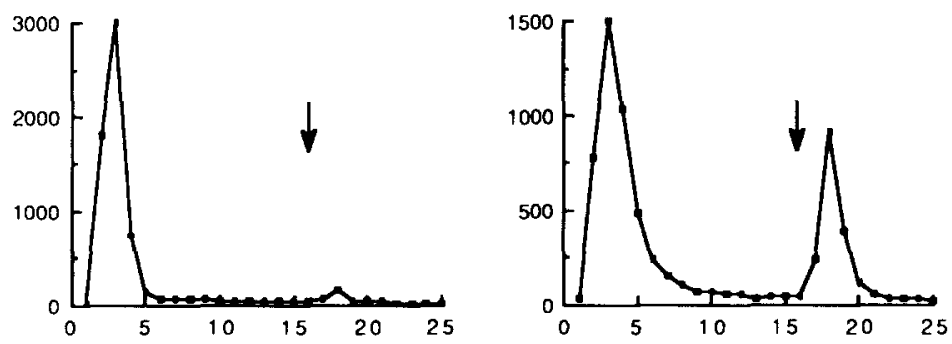

FRACTION NUMBER

FIG. 8. Affinity chromatography of $\left[{ }^{125} \mathrm{I}\right] \mathrm{MPR}-2$ fractions from an Ultrogel AcA 34 column. $\left[{ }^{125} \mathrm{I}\right] \mathrm{MPR}-2$ peaks a, b, and c (each contained approximately $7000 \mathrm{cpm}$, see Fig. 5) were chromatographed separately on $1 \times 2.5$-cm agarose-pentamannosephosphate columns preequilibrated with buffer A containing, or lacking, $10 \mathrm{mM} \mathrm{MnCl}$ as indicated in the figure. After washing, the columns were eluted with the same buffers containing $5 \mathrm{~mm}$ Man-6-P. The point of addition of buffer containing Man-6-P is indicated by the arrows. Fractions 1-4, flow-through; fractions $5-16$, retarded; and fractions $17-25$, bound.

peaks $a, b$, and $c$ were bound tightly to the affinity column and were eluted with Man-6-P, indicating the higher oligomers were more strongly bound to the affinity column whereas the major portion $(90 \%)$ of peak c, presumably monomer, passed directly through the column without retardation. When $10 \mathrm{mM} \mathrm{MnCl}$ was included in the buffer, 82,75 , and $28 \%$, respectively, of the total ${ }^{125}$ I present in peaks $a, b$, and $c$ were bound to the column while in this case only $53 \%$ of peak c passed directly through the column. These results suggest that the higher the oligomeric form of MPR-2 the greater is its affinity for ligand.

To examine the ability of divalent cations to potentiate aggregation, peak $\mathbf{c}$ (monomer) was rechromatographed on a standardized Ultrogel AcA 34 column preequilibrated and run with buffer $\mathrm{C}$ containing $10 \mathrm{mM}$ $\mathrm{MnCl}_{2}$. The ${ }^{125}$ I elution profile obtained in the presence of $\mathrm{Mn}^{2+}$ was identical to that obtained in the absence of $\mathrm{Mn}^{2+}$ (data not shown). These results suggest that $\mathrm{Mn}^{2+}$ does not change the oligomeric state of the receptor and that the increased affinity of the monomer and dimer species of MPR-2 observed in the presence of $\mathrm{Mn}^{2+}$ was not attributable to the formation of higher oligomeric species.

\section{DISCUSSION}

The above-described results suggest that intrachain disulfide bonds of MPR-2 are important for maintaining the conformation of MPR-2 for ligand binding. This finding confirms the finding of Hille et al. who reduced human liver MPR-2 with DTT in the presence of urea (26). However, in the present studies with bovine receptor urea was not necessary for the reduction and loss of ligand binding activity. The drastic alteration in antibody binding observed upon reduction of bovine receptor suggests that the receptor is unfolded by reduction.

The present studies indicate that bovine testicular MPR-2 exists in cell membranes primarily as a dimer. This finding corroborates the finding of Stein et al. with the transformed human monocyte cell line (U937) (14) and the finding of Dahms and Kornfeld with bovine CD- 
MPR-transfected mouse L cells (15). Additionally, the present results are in agreement with the finding of Stein et al. with purified human liver MPR-2 that purified MPR-2 receptor exists in solution largely as a tetramer (16). On the other hand, Dahms and Kornfeld have reported that MPR-2 purified from $X$. laevis oocytes injected with bovine MPR-2 RNA exists as a dimer (15).

The formation of tetramer during purification cannot be attributed to the solubilization step since crosslinking experiments detected the dimer, but not the tetramer, in the membrane extracts (Fig. 4A). The tetramer was detected only after the membrane extract was subjected to affinity chromatography (Fig. 4C). These results suggest that the aggregation of the MPR-2 dimer to form the tetramer occurred during the affinity chromatography purification step. The formation of tetramer is probably not attributable to the binding of the receptor to the immobilized ligand, since Man-6-P did not affect the aggregation of the receptor. However, the formation of oligomeric species may be attributable to the fact that the receptor molecules exist in a more highly concentrated form and are brought into close proximity when adsorbed to the affinity matrix, thereby promoting formation of oligomeric species. This hypothesis is supported by the observation that when ${ }^{125}$ I] MPR-2 was chromatographed on Ultrogel AcA 34, the receptor preparation was resolved into tetramer, dimer, and monomer species (Fig. 5). When the [ $\left.{ }^{125} \mathrm{I}\right] \mathrm{MPR}-2$ was mixed with a large excess of unlabeled MPR-2, $>90 \%$ of the $\left[{ }^{125} \mathrm{I}\right]-$ MPR-2 migrated as a tetramer. These results suggest that aggregation and dissociation of MPR-2 are largely concentration dependent and may explain the different finding of Dahms and Kornfeld that purified bovine MPR-2 translated in $X$. laevis exists as a dimer (15). In their experiments the receptor was isolated from pulselabeled cells in very low concentrations, a condition that does not favor tetramer formation.

While this manuscript was in preparation Waheed et al. (27) reported that aggregation and dissociation of MPR-2 were affected by $\mathrm{pH}$ and Man-6-P. At $\mathrm{pH} 7.5$ the MPR-2 dimer aggregated to form the tetramer. The equilibrium between dimer and tetramer was reached at $4^{\circ} \mathrm{C}$ in 6-8 days. At $\mathrm{pH} 4.5$ the MPR-2 tetramer dissociated into the dimer. At $\mathrm{pH} 7.5$ the presence of Man-6-P shifts the equilibrium toward the formation of the tetramer. In contrast, in the presently described studies, incubation of the dimer in the presence of Man-6-P did not promote the formation of the tetramer. This may be attributed to differences in incubation time used. Waheed et al. observed the effect of Man-6-P on the aggregation of the receptor in a course of several days. In the presently described experiments, MPR-2 preparations were incubated with Man-6-P for only $4 \mathrm{~h}$ (Fig. 4). This short incubation time with Man-6-P may not be of sufficient duration to promote formation of detectable tetramer.
Present studies revealed that potentiation of binding of ligand to receptor occurs during aggregation. This aspect of the aggregation process has not been previously addressed. The binding affinity of MPR-2 to agarosepentamannosephosphate increased dramatically with the size of the oligomer species. The mechanism for enhanced binding of receptor to ligand is not readily apparent. The conformation of the receptor may change during aggregation in a fashion that promotes greater accessibility of the binding pocket. Alternatively, multiple pentamannosephosphate residues may interact simultaneously with the aggregates, forming a more stable complex. In contrast, monomeric species may bind only a single pentamannosephosphate residue. Evidence has been obtained in this laboratory, and by others, that suggests oligosaccharides containing two Man-6-P residues have greater affinity for both high and low molecular weight mannose 6-phosphate receptors than oligosaccharides containing one Man-6-P residue $(12,13)$. Whether biantennary oligosaccharides containing two terminal Man-6-P residues bind more favorably to the monomeric receptor species than oligosaccharides carrying a single Man-6-P residue remains to be established.

The addition of $\mathrm{Mn}^{2+}$ enhanced binding of MPR-2 to immobilized pentamannosephosphate affinity column, especially the dimer and monomer forms. Although binding of peak a (tetramer) was also increased by $\mathbf{M n}^{2+}$ (Fig. 8), it is possible that this increase was attributable to the presence of dimer and monomer species along with the tetramer form in peak a (Fig. 7). If such was the case, the tetramer itself may not require $\mathrm{Mn}^{2+}$ to bind to the affinity column even if $\mathrm{Mn}^{2+}$ may somehow increase its affinity. Reports as to the requirement of divalent cations for the ligand binding activity of the receptor are at variance. It was originally reported that divalent cations were absolutely required for ligand binding activity of membrane-bound receptor (28). Subsequent studies with soluble receptor preparations suggested that divalent cations enhanced but were not strictly required for ligand binding (29-31). This discrepancy may be attributable to different receptor preparations containing differing levels of oligomeric forms of the receptor, a situation that would be anticipated to result in an apparent difference in the requirement for divalent cations in the binding of receptor to ligand.

Since peak $c$ was composed essentially of monomer and $\mathrm{Mn}^{2+}$ did not promote its aggregation, the monomer form of MPR-2 has the ability to bind ligand. This finding is in agreement with the finding of Dahms and Kornfeld that the truncated receptor monomer is able to bind to agarose-pentamannosephosphate (15). However, the affinity of ligand for the monomer is much lower than that exhibited for the oligomeric species. Indeed, its affinity for ligands carrying Man-6-P is totally dependent on the presence of $\mathrm{Mn}^{2+}$ (Fig. 8). 
On the basis of the above observations, it is suggested that studies concerned with the binding properties of the receptor must take into consideration the aggregation state of the receptor preparations.

\section{ACKNOWLEDGMENT}

We gratefully acknowledge the expert assistance of Ms. Helen M. $\mathrm{Wu}$ in the typing of this manuscript.

\section{REFERENCES}

1. Distler, J., Hieber, V., Sahagian, G., Schmickel, R., and Jourdian, G. W. (1979) Proc. Natl. Acad. Sci. USA 76, 4235-4239.

2. von Figura, K., and Hasilik, A. (1986) Annu. Rev. Biochem. 55, 167-193.

3. Kornfeld, S. (1986) d. Clin. Invest. 77, 1-6.

4. Sahagian, G. G., Distler, J., and Jourdian, G. W. (1981) Proc. Natl. Acad. Sci. USA 78, 4289-4293.

5. Steiner, A. W., and Rome, L. H. (1982) Arch. Biochem. Biophys. 214, 681-687.

6. Hoflack, B., and Kornfeld, S. (1985) J. Biol. Chem. 260, 12,00812,014 .

7. Distler, J., and Jourdian, G. W. (1985) Fed. Proc. Fed. Amer. Soc. Exp. Biol. 44, 1435.

8. Dahms, N. M., Lobel, P., Breitmeyer, J., Chirgwin, J. M., and Kornfeld, S. (1987) Cell 50, 181-192.

9. Lobel, P., Dahms, N. M., and Kornfeld, S. (1988) J. Bivl. Chem. 263, 2563-2570.

10. Oshima, A., Nolan, C. M., Kyle, J. W., Grubb, J. H., and Sly, W. S. (1988) J. Biol. Chem. 263, 2553-2562.

11. Pohlmann, R., Nagel, G., Schmidt, B., Stein, M., Lorkowski, G., Krentler, C., Cully, J., Meyer, H. E., Grzeschik, K-H., Mersmann, G., Hasilik, A., and von Figura, K. (1987) Proc. Natl. Acad. Sci. USA 84, 5575-5579.

12. Hoflack, B., Fujimoto, K., and Kornfeld, S. (1987) J. Biol. Chem. 262, 123-129.
13. Jourdian, G. W., Li, M., and Distler, J. J. (1987) Protides Biol. Fluids 35, 395-398.

11. Stein, M., Braulke, T., Krentler, C., Hasilik, A., and von Figura, K. (1987) Biol. Chem. Hoppe-Seyler 368, 937-947.

15. Dahms, N. M. and Kornfeld, S. (1989) J. Biol. Chem. 264, 11,45811,467 .

16. Stein, M., Meyer, H. E., Hasilik, A., and von Figura, K. (1987) Biol. Chem. Hoppe-Seyler 368, 927-936.

17. Wendland, M., Hille, A., Nagel, G., Waheed, A., and von Figura, K. (1989) Biochem. J. 260, 201206.

18. Li, M., Distler, J., and Jourdian, G. W. (1988) Fed. Proc. Fed. Amer. Soc. Exp. Biol. 47. 7290.

19. Distler, J. J., and Jourdian, G. W. (1987) in Methods in Enzymology (Ginsburg, V., Ed.), Vol. 138, pp. 504-509, Academic Press, San Diego.

20. Li, M., Distler, J. J., and Jourdian, G. W. (1989) in Methods in Enzymology (Ginsburg, V., Ed.), Vol. 179, pp. 304-310, Academic Press, San Diego.

21. Lazarides, E. (1976) J. Supramol. Struct. 5, 531-563.

22. Hurn, B. A. L. and Chantler, S. M. (1980) in Methods in Enzymology (van Vunakis, H. and Langone, J. J., Ed.), Vol. 70, pp. 104 142, Academic Press, San Diego.

23. Ouchterlony, O. (1949) Arkiv. Kemi. 1, 43.

24. Laemmli, U. K. (1970) Nature (London) 227, 680-685.

25. Burnette, W. N. (1981) Anal. Biochem. 112, 195-203.

26. Hille, A., Waheed, A., and von Figura, K. (1989) J. Biol. Chem. 264, 13,460-13,467.

27. Waheed, A., Hille, A., Junghans, U., and von Figura, K. (1990) Biochemistry 29, 2449-2455.

28. Hoflack, B. and Kornfeld, S. (1985) Proc. Natl. Acad. Sci. USA 82, 4428-4432.

29. Distler, J. J., Patel, R., and Jourdian, G. W. (1987) Anal. Biochem. 166, 65-71.

30. Stein, M., Zijderhand-Bleekemolen, J. E., Geuze, H., Hasilik, A., and von Figura, K. (1987) EMBO J. 6, 2677-2681.

31. Junghans, U., Waheed, A., and von Figura, K. (1988) FEBS Lett. 237, 81-84. 